\title{
A critical review of the methods of analysis for folded plate structures
}

\author{
H. R. EVANS \& K. C. ROCKEY
}

\section{Dr K. P. Osborne, W. S. Atkins \& Partners}

In their outline of the 'ordinary methods' the Authors consider that the loads are resisted wholly by the slab system and that the reactions of this system are applied to the plates system (Fig. 4). This approach is found convenient where loads are parallel to each other as in gravity loading, and is used in many analyses. However, for loads which are not parallel it may be found easier to use the strictly correct splitting of loads in which components of loading normal to the plates are considered to be applied to a slab structure, and the resulting fold reactions applied to the plate structure, together with the component of the distributed load parallel to each plate. In the approach adopted by the Authors the distributed applied load is considered to be divided into two concentrated loads acting at each edge of the plate giving errors in the magnitude and distribution of the transverse planar forces, although the algebraic sum of these forces in each plate will be the same in both approaches. The correct determination of these transverse planar forces could be important where a check on plate buckling is required.

50. As the Authors point out in their conclusions, the Paper is concerned with a comparison of the four common groups of analysis of folded plates using the five basic assumptions listed in $\S 7$ of which they question the validity of the imposed end restraint, but deal with this topic elsewhere. ${ }^{14}$ However, the basic assumption that the material is homogeneous and elastic is also open to doubt in the common case of a reinforced concrete folded plate. Numerous tests on reinforced concrete models including those by Syracuse University, ${ }^{15}$ Aldridge, ${ }^{16}$ Goble and Juodikis, ${ }^{17}$ and Osborne $^{18}$ have concluded that the assumption of a homogeneous structure in the post-cracking stage can lead to considerable error. For these reasons care should be taken before selecting one of these conventional methods that the properties of the structure will correspond to those assumed for the analysis.

\section{Dr G. B. Waterworth, Mott, Hay \& Anderson}

The main conclusion reached appears to be that methods $2 \mathrm{a}$ and $2 \mathrm{~b}$ are unreliable in the short wide plate range $1 / h \leqslant 3$ and method $2 a$ is less reliable than $2 b$ as this ratio increases beyond 3. It is worthwhile recalling that in 1935 Schorer produced a simplified version of the rigorous cylindrical shell equation which has since proved unreliable in the so-called short shell category. The physical assumptions on which it was based are similar to those in methods $2 \mathrm{a}$ and $2 \mathrm{~b}$, and it is therefore not really surprising to find that the latter, qualitatively at least, are also unreliable in the short plate range. This conclusion is of course well known ${ }^{19,20}$ and by means of two theoretical plate models the Authors have demonstrated the extent to which shear strain and secondary plate bending are influenced by plate length. In passing, it is of interest to note that it is the inclusion of curvature terms in the Maxwell-Airy biharmonic equation for plane stress and the Sophie-Lagrange equation associated with plate bending (i.e. the two actions referred to in $\S 9$ ) which give rise to the greater structural efficiency of curved shells mentioned in $\S 3$.

52. The Authors have not indicated that as the $l / h$ ratio decreases arch stresses

Paper published: Proc. Instn Civ. Engrs, 1971, 49 (June) 171-192. 


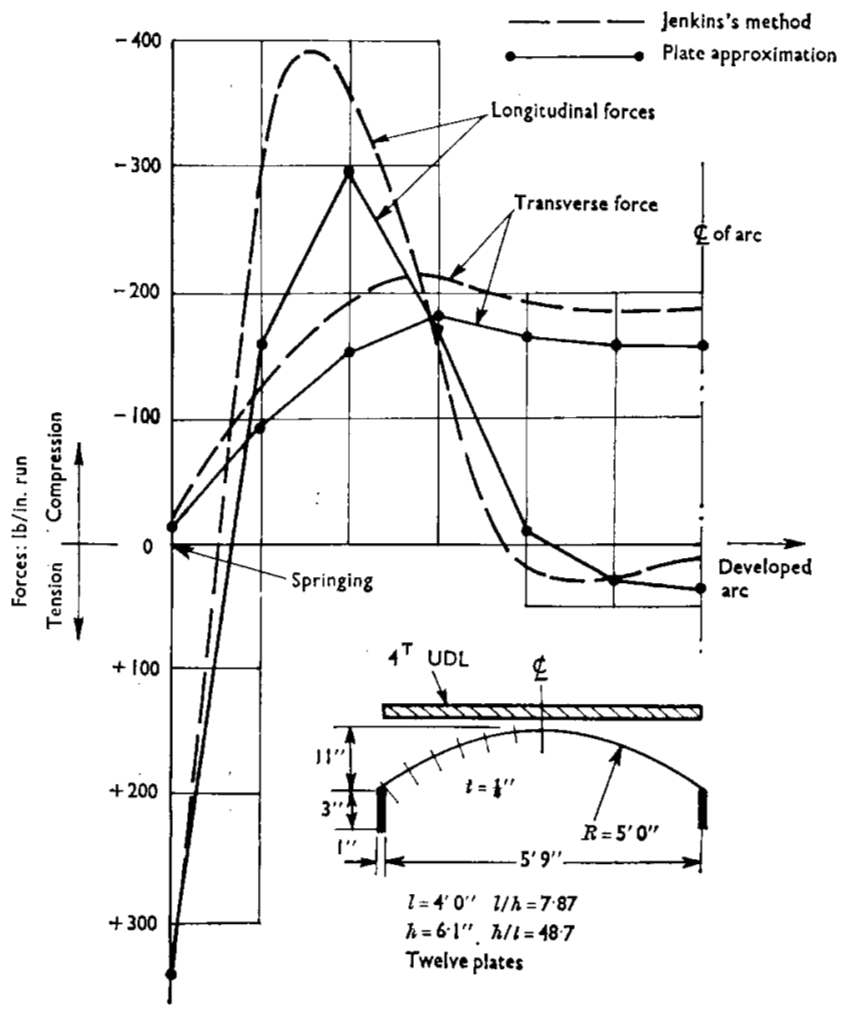

Fig. 16. Longitudinal and transverse forces for a typical short prismatic shell

increase in significance in relation to longitudinal stresses. Figs 16 and 17 show comparisons of arch thrust and longitudinal force at mid-span for a short steel shell and a long concrete shell vault respectively. In both cases the plates are meant to substitute the cylindrical surface shown. Transfer matrix techniques ${ }^{21}$ based on method $2 \mathrm{~b}$ were used to obtain the forces and Jenkins's method has been applied to the equivalent cylinders in each case for comparison. It can be seen that whereas the maximum arch thrust is about one-tenth the maximum longitudinal force for the long shell it is almost two-thirds of this maximum value for the short shell. It will be apparent also that the approximate method underestimates both sets of forces when compared to the rigorous solution confirming more or less the trends in Fig. 8. Shear forces are not dealt with although they are of considerable importance in the design of reinforced or prestressed concrete structures. In general, however, they exhibit the same degree of inaccuracy encountered in other planar forces.

53. Mehmel and Schwartz ${ }^{22}$ in a comparison of approximate methods for cylindrical shells investigated a parameter describing the shallowness defined approximately by the ratio between span and rise. For the plate roof shown in Fig. 1 and Fig. 6(c) the study of a similar variable ought to be considered because there is clearly a limit to the effective in-plane stiffness contribution from the very inclined plates of a shallow roof. Restricting the survey to only two commonly occurring plate configura- 

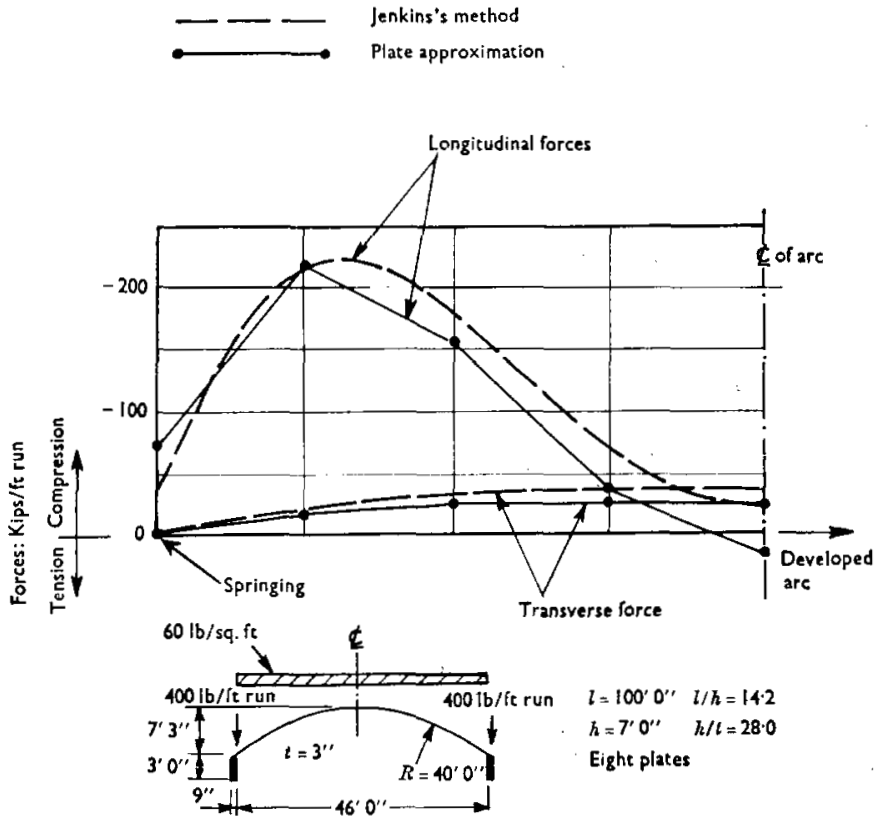

Fig. 17. Longitudinal and transverse forces for a typical long prismatic shell

tions is a reasonable solution to the problem of result presentation but a little more information might have been given for the vaulted type roofs. For instance does the variation of $h / t$ have the same effect on transverse moments for vaulted plates as it appears to do on trough types in Fig. 11, method $2 b$ ?

54. It is widely known that the beam method is unsuitable for all but the most rudimentary of preliminary design checks and even then when horizontal displacements are known to be severely limited as at the internal joints of a multi-bay roof. Its inclusion here seems to be superfluous except for the fact that the results obtained demonstrate again the degree of error to be expected if indiscriminately applied.

55. Finally, I believe that the Authors have provided some valuable information on the relative accuracy of the approximate methods but their study has been somewhat limited in its scope. After introducing the subject with a reference to vaulted type roofs and an undertaking to establish the fields of application of the various methods most of the text and results concentrate only on the trough type plates. The point I wish to make concerns the need for additional work in this field and is really outside the context of the Paper. For economic reasons individual plates are frequently precast on a factory production basis, assembled as units to be lifted into place or just erected with joints made in situ. They are sometimes prestressed to increase spans, reduce weight or reduce cracking. Owing to construction and erection problems creating awkward boundary conditions it is often difficult to apply the approximate methods with certainty, resulting in poor economy or an alternative design. Some idea of the scope of the methods would therefore be valuable. For example what would be the minimum number of plates required to apply method $2 b$ successfully given no physical restraint at the lateral boundary? Is the accuracy obtained by this method compatible with that required to assess the effect of individual plate deformations resulting from large prestressing forces? Speed of application 
may be a decisive factor in choosing a particular method and could well be pursued as a further investigation. If the Authors have already considered some of these points I would appreciate their comments.

\section{Professor J. E. Gibson, The City University, London}

The Authors are to be congratulated on their review of the various methods for the analysis of folded plate structures. I have also observed the inaccuracies of the beam method in my own investigations, although as the Authors have indicated their investigation has been restricted in the main to the analysis and testing of relatively thin plate structures. Nevertheless, as a preliminary design method to check on the initial sizes of plate members, the beam method is exceedingly quick and less inaccurate when applied to the relatively thicker plates as used in reinforced concrete folded plate structures.

57. Another approach to the elastic analysis of folded plates which $I$ have used ${ }^{23-26}$ is perhaps worthy of mention, namely the degenerate technique. In this method the general theory for cylindrical shells is used and the resulting eighth-order partial differential shell equation is solved. This is the combined equivalent of the two fourth-order partial differential equations for bending and plate action of the elastic theory for folded plates, as used by the Authors in developing their computer program termed method 1. The technique is essentially a computer method as it demands the use of a general program for analysing cylindrical shells.

58. In the degenerate theory for folded plates, normal shell theory is utilized and the circular surface is caused to degenerate into a flat or plane surface by decreasing the half angle of the cylindrical surface to $1^{\circ}$ and suitably increasing the radius of the cylindrical surface so that the required width of the plate element is achieved.

59. Consider Fig. 18 which represents a section through a degenerate cylindrical surface of radius $R$ and half angle of $1^{\circ}$. The flatness of the resulting surface may be measured by the ratio of the rise $\delta$ to the chord $C$ thus:

$$
\text { flatness ratio }=\delta / C=R\left(1-\cos 1^{\circ}\right)=2 R \sin 1^{\circ}=1 / 230
$$

This is a sufficient degree of flatness for all practical purposes: the necessary radius $R$ required to generate the chord width $C$ will then be given by:

$$
R]=\left[C / 2 \sin 1^{\circ}=C / 0.035\right.
$$

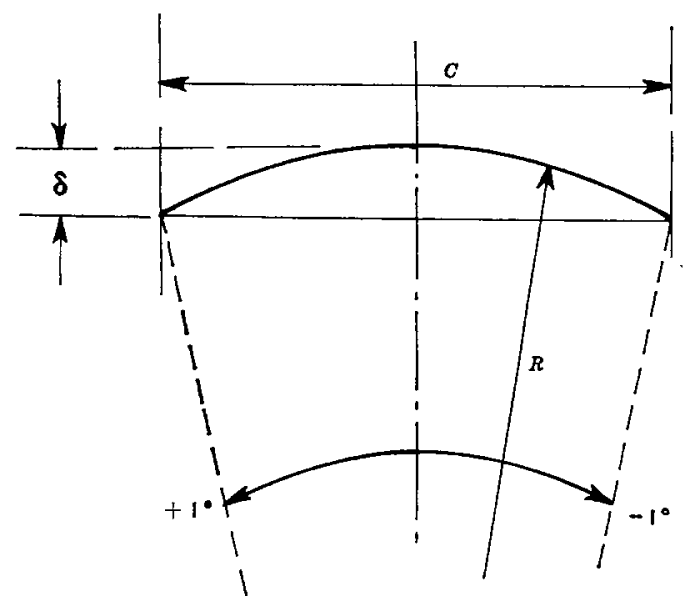

Fig. 18 
60. Using this technique any computer program that analyses cylindrical shells may then be used to analyse plates. If the program is general and thus capable of analysing multicylindrical shells of any geometric transverse section, then folded plate structures may also be analysed by this program using this degenerate technique. A typical general cross section which has been used in developing a program for multicylindrical shells is shown in Fig. 19(a), in which it may be seen that the cross section is controlled completely by the radius $R$, the half angle $\phi$ and the inclination $\beta$ of the centreline of each shell to the vertical.

61. In preparing the data for the program to analyse the folded plate model (Fig. 6(a)) used by the Authors in their experimental investigation, the radii must be suitably selected using $R=C / 0.035$, the slopes of the plates being defined by the angles $\beta$; all half angles $\phi$ must of course be $1^{\circ}$ (as shown in Fig. 19(b)).

62. The necessary input data then include the following:

$$
\begin{aligned}
& \text { for plate (1) } \phi=1^{\circ}, R=2 \cdot 12 / 0 \cdot 035=60 \cdot 6, \beta=+90^{\circ} ; \\
& \text { for plate (2) } \phi=1^{\circ}, R=6 \cdot 36 / 0 \cdot 035=182, \beta=+45^{\circ} ; \\
& \text { for plate (3) } \phi=1^{\circ}, R=182, \quad \beta=-45^{\circ}
\end{aligned}
$$

and so on.

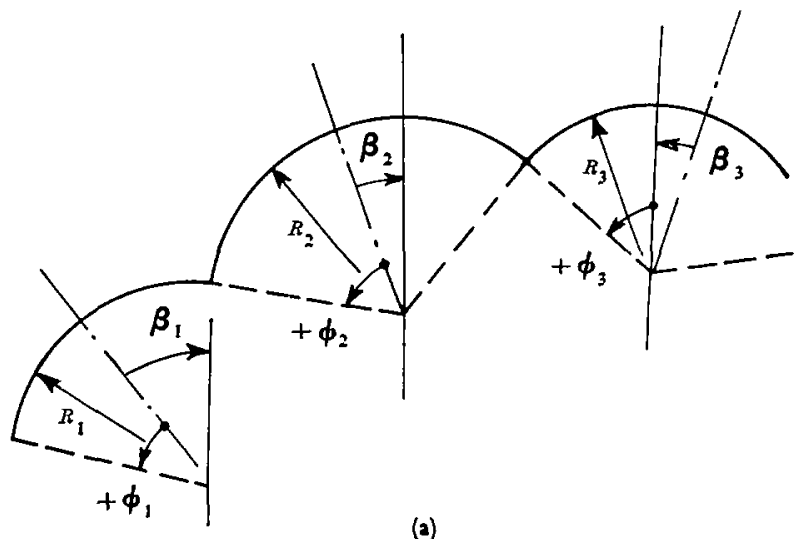

(a)

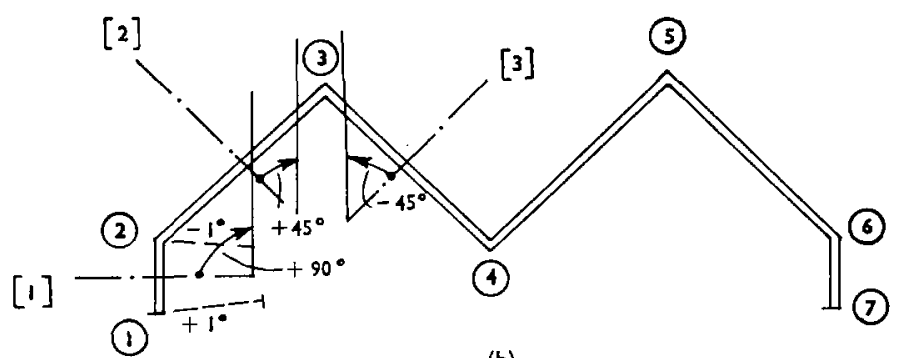

(b)

Fig. 19 


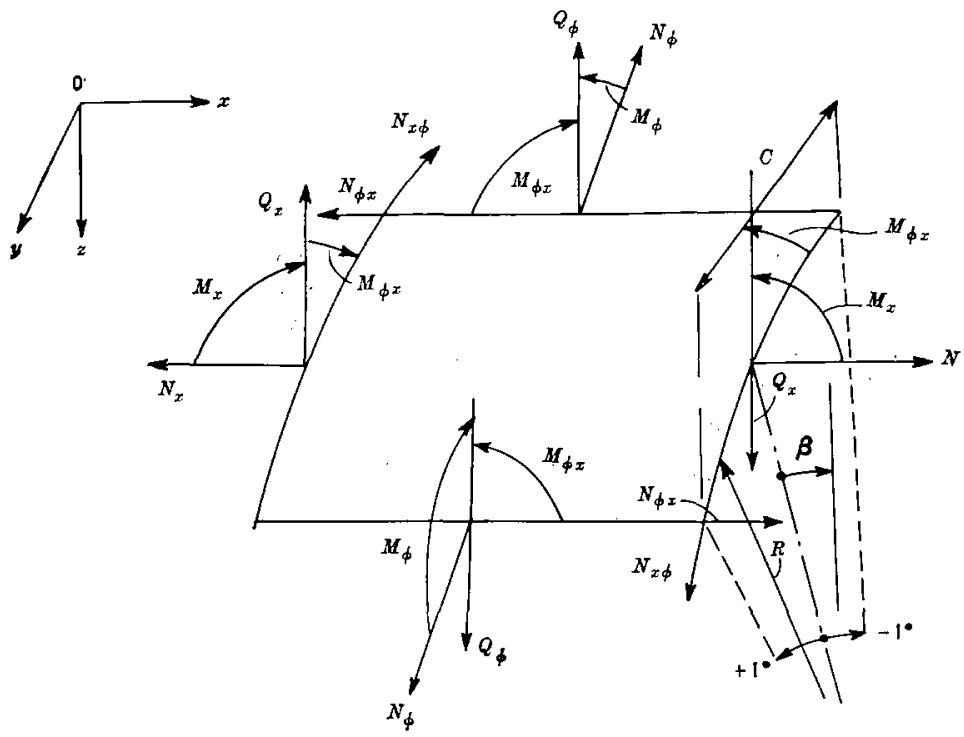

Fig. 20

63. The stress resultants generated by the program are as shown in Fig. 20; all moment resultants $M_{x}, M_{\phi}, M_{x \phi}, M_{\phi x}$ are moments per unit width, whilst force resultants $N_{x}, N_{\phi}, N_{\phi x}=N_{x \phi}, Q_{x}$ and $Q_{\phi}$ are forces per unit width; their positive directions are as shown in the figure. Some of the results for this trough type model for a 72 in. span are given in Table 3 in which the extreme edges of the plate are designated $+1^{\circ}$ and $-1^{\circ}$ as shown in Fig. 20 .

64. Only the values underlined in Table 3 may be directly compared with those given by the Authors in Table $1 . N_{x}$ must be converted to the stress $f_{x}$ by:

$$
f_{x}=N_{x} / t=N_{x} / \cdot 08=12 \cdot 5 N_{x}
$$

and as $w$ is the deflexion normal to the plate this must be multiplied by $\cos 45^{\circ}$ to give the vertical ridge deflexions listed by the Authors. With these conversions the following comparisons may be made for the $72 \mathrm{in.} \mathrm{span} \mathrm{and} \mathrm{for} \mathrm{the} 36 \mathrm{in.}$ and $18 \mathrm{in}$. spans.

65. The agreement between these results is seen to be good, as is to be expected, since both methods are derived from linear elastic theory. The remaining results for Table 2 showed similar agreement.

66. In a review of this nature perhaps the Authors should have mentioned the work of Scordelis ${ }^{27}$ as he originally programmed the elastic theory of Yitzhaki for computer. Further, as far as I am aware Scordelis was the first to use aluminium models to study the experimental behaviour of folded plate structures. ${ }^{25,28}$

67. Finally perhaps the Authors might have mentioned the use of finite element techniques for the analysis of folded plates. Programs using this technique it is appreciated however are extremely time-consuming because of the large number of simultaneous equations that are involved. Thus to analyse a single plate a mesh, say, $8 \times 6$ involving some 50 nodes with six degrees of freedom at each node would have to be used. This yields 300 simultaneous equations and for the six plates used in the 
Table 3. Stress resultants and deflexions for trough type section, length $72 \mathrm{in}$. and symmetrical loading

\begin{tabular}{|c|c|c|c|c|c|c|}
\hline$\phi$ & Ridge no. & $\begin{array}{c}M_{\phi}, \\
\text { lb in./in. }\end{array}$ & $\begin{array}{l}N_{\phi}, \\
\text { lb/in. }\end{array}$ & $\begin{array}{l}N_{x} \\
\text { lb/in. }\end{array}$ & $w$ & $\begin{array}{l}N_{x \phi \phi}, \\
\text { lb/in. }\end{array}$ \\
\hline$+1^{\circ}$ & (1) or (7) & 0.00 & 0.00 & $232 \cdot 17$ & 0.09390 & 0.00 \\
\hline $\begin{array}{r}0^{\circ} \\
-1^{\circ}\end{array}$ & $(2)$ or $(6)$ & $\begin{array}{l}0.02 \\
0.04\end{array}$ & $\begin{array}{l}-0.20 \\
-0.63\end{array}$ & $\begin{array}{r}\overline{106 \cdot 21} \\
-16.99\end{array}$ & $\begin{array}{l}0.08165 \\
0.06934\end{array}$ & $\begin{array}{l}-7 \cdot 80 \\
-9 \cdot 85\end{array}$ \\
\hline
\end{tabular}

Plate (1)

\begin{tabular}{r|l|r|r|r|r|r}
\hline$+1^{\circ}$ & (2) or $(6)$ & 0.04 & -0.46 & -16.99 & 0.10280 & -9.85 \\
$0^{\circ}$ & & -0.04 & -1.54 & -52.51 & 0.05864 & -4.97 \\
$-1^{\circ}$ & (3) or $(5)$ & -3.21 & -1.62 & -85.09 & 0.02159 & 4.58 \\
\hline
\end{tabular}

Plate (2)

\begin{tabular}{r|c|r|r|r|r|r}
\hline$+1^{\circ}$ & (3) or (5) & -3.21 & -1.55 & -85.09 & 0.007248 & 4.58 \\
$0^{\circ}$ & & 0.21 & -0.43 & 16.21 & 0.013551 & $9 \cdot 34$ \\
$-1^{\circ}$ & (4) & 0.51 & 0.39 & $\underline{119.26}$ & 0.021061 & 0.00 \\
\hline
\end{tabular}

Plate (3)

Table 4. Comparison of stresses and deflexions as given by the elastic plate theory and the shell degenerate theory

\begin{tabular}{|c|c|c|c|c|c|c|}
\hline $\begin{array}{c}\text { Length, } \\
\text { in. }\end{array}$ & Ridge no. & $\begin{array}{l}N_{x} \\
\text { lb/in. }\end{array}$ & $\begin{array}{c}f_{x} \\
l b / s q . \text { in } \\
\text { Gibson }\end{array}$ & $\begin{array}{l}f_{x}, \\
\text { lb/sq.in. } \\
\text { Evans }\end{array}$ & $\begin{array}{l}w \times 10^{-4} \\
\text { Gibson }\end{array}$ & $\begin{array}{c}w \times 10^{-4} \\
\text { Evans }\end{array}$ \\
\hline 72 & $\begin{array}{l}(4) \\
(5) \\
(7) \\
(6)\end{array}$ & $\begin{array}{r}119 \cdot 26 \\
-85 \cdot 09 \\
232 \cdot 17 \\
\end{array}$ & $\begin{array}{r}1480 \\
-1068 \\
2900 \\
-\end{array}$ & $\begin{array}{r}1420 \\
-1040 \\
2710 \\
-\end{array}$ & $\bar{z}$ & $\frac{\bar{C}}{\overline{737}}$ \\
\hline 36 & $\begin{array}{l}(4) \\
(5) \\
(7) \\
(6)\end{array}$ & $\begin{array}{r}276 \cdot 1 \\
-112 \cdot 7 \\
1013 \cdot 7 \\
-\end{array}$ & $\begin{array}{r}344 \\
-142 \\
1268 \\
--\end{array}$ & $\begin{array}{r}337 \\
-142 \\
1270 \\
-\end{array}$ & $\bar{z}$ & $\frac{-}{\overline{103}}$ \\
\hline 18 & $\begin{array}{l}(4) \\
(5) \\
(7) \\
(6)\end{array}$ & $\begin{array}{r}75 \cdot 2 \\
-13 \cdot 8 \\
288 \cdot 8 \\
-\end{array}$ & $\begin{array}{c}94 \\
-17 \cdot 2 \\
361 \\
-\end{array}$ & $\begin{array}{r}87 \cdot 8 \\
-34 \cdot 6 \\
364 \cdot 0 \\
-\end{array}$ & $\frac{-}{7 \cdot 86}$ & $\frac{\bar{z}}{8 \cdot 07}$ \\
\hline
\end{tabular}

Authors' experimental model this would require inverting a diagonal band matrix of the order of 3000 .

68. Using this program and indeed that of the Authors, only eight simultaneous equations per plate are required, giving only 48 equations to invert. 


\section{Dr Evans and Professor Rockey}

The point made by Dr Osborne in $\$ 49$ is that rather than splitting up the loading as shown in Fig. 4 of the Paper, a different system could be used in which the component of the external loading normal to the plane of each plate is applied to the slab system and the in-plane component is applied to the plate system. This alternative system is much more convenient in the general case when the loads applied to the various plates are not parallel, and the computer program developed by the Authors did in fact employ sych a system. Fig. 4 was used in the Paper simply as a convenient diagrammatic representation of the structural action. However, it should be noted that the results obtained from an elastic analysis by methods $2 a$ and $2 b$ will be exactly the same whichever system of load splitting is used, because, during the analysis of each plate as a beam in the longitudinal analysis, the methods assume a uniform distribution of the in-plane load across the width of the plate. As Dr Osborne points out, special attention to the actual distribution of the loads may be necessary when considering the buckling of a component plate.

70. Dr Osborne also points out in $\S 50$ that, in common with many other analytical techniques, the methods assume a homogeneous, elastic material and these assumptions are open to question in the case of reinforced concrete structures. Another assumption that is perhaps worthy of further consideration is that the longitudinal joints between plates are fully monolithic. In the case of factory produced precast units, as mentioned by Dr Waterworth in $\S 55$, the provision of full continuity across joints made in situ might be difficult.

71. The Authors regret that they as yet have insufficient information about the behaviour of vault type roofs to answer all the points made by $\mathrm{Dr}$ Waterworth. The suggestion in $\S 53$ that a parameter analogous to the span/rise parameter should be investigated is very interesting and this investigation can be done conveniently with the programs developed by the Authors. Certainly the importance of the in-plane stiffness can be expected to increase relative to the importance of the out-of-plane stiffness as the rise of the cross-section increases.

72. Dr Waterworth also asks about the assumed boundary conditions. The methods all assume that the end diaphragms permit all movements normal to their planes but are sufficiently stiff to restrict all movements in their planes. Yitzhaki ${ }^{7}$ has shown how other end conditions can be considered in methods $2 a$ and $2 b$. Various support conditions and the longitudinal edges can be taken into account and the type of support should not affect the accuracy of method $2 b$, e.g. if the small skirt plates ( 1 and 6 ) had been omitted from the models considered in the Paper, then the outer sloping plates ( 2 and 5 ) would be analysed as long cantilevers in the transverse slab analysis and the solution procedure would not be affected.

73. Method $2 \mathrm{~b}$ can also be used to assess the effect of prestressing forces and this has been further discussed by Yitzhaki. ${ }^{7}$

74. In $\S 55$, Dr Waterworth raises the important question of the speed of application of the various methods. Both the beam method and method $2 \mathrm{a}$ can be applied fairly easily as a hand solution, but for structures in which a sway correction is necessary, therefore involving method $2 b$, the amount of computation increases significantly although a hand solution is still possible. Method 3 is not really amenable to a hand solution and a computer solution is required. However the computer time involved would be small for the solution of a quite complex structure.

75. In discussing solution times, the point made by Professor Gibson in $\S 67$ should be noted, as he discusses the application of the finite element technique to folded plates and points out the extensive computations that this method involves. The Authors have discussed this method extensively in a previous publication, ${ }^{29}$ and have shown the adaptability of the method to the analysis of structures with various end conditions in reference 14 . Thus the extensive computations required in a finite element solution must be balanced against its extreme adaptability. In fact, there 
are many cases, such as folded plates with window openings or folded plates supported by randomly placed columns, where the finite element approach offers the only means of solution.

76. It is also of interest to note the excellent agreement between Professor Gibson's degenerate shell theory and the elasticity method discussed in the Paper. This certainly shows that a shell analysis program can be used for folded plate solutions and perhaps by similar reasoning also it should be possible to apply folded plate programs to the analysis of curved shells suitably simulated by a series of flat plates.

77. Finally, the Authors agree with Professor Gibson as to the great contribution made by Scordelis to the field of folded plate analysis. Scordelis' work was not discussed in the Paper as it was restricted to the consideration of the basic analytical techniques. The work done by Scordelis in the application of these methods and particularly his experimental work on the aluminium northlight shell model has been of much interest to the Authors and has been discussed in reference 14.

\section{References}

14. Rockey K. C. and Evans H. R. A study of the behaviour of folded plate structures. Struct. Engr, 1971, 49 (April) 189-197.

15. SyRACUSE UNIVERSITY. Test of a reinforced concrete folded plate structure. Report No. 335-5910F, Syracuse University Research Institute, Syracuse, New York, 1959.

16. ALDRIDGE W. W. Ultimate strength tests of model reinforced concrete folded plate structures. University of Texas, $\mathrm{PhD}$ thesis, 1966.

17. Goble G. G. and Juodikis A. Reinforced concrete folded plate behaviour. IASS Symposium. Leningrad, 1966.

18. OSBORNE K. P. Experimental and theoretical studies of prismatic folded plate structures. University of Strathclyde, PhD thesis, 1970.

19. Schorer H. Line load action in thin cylindrical shells. Proc. Am. Soc. Civ. Engrs, 1935, 61.

20. Bouma A. L. On approximate methods of shell analysis; a general survey. World conference on shell structures, San Francisco, 1962.

21. Schegg A. and Cudmani R. O. Analysis of prismatic folded plate structures by transfer matrices. Indian Concr. Jnl, 1965.

22. Mehmel A. and Schwartz H. Investigations on the limits of validity of approximate methods of design of circular cylindrical shells. World conference on shell structures, San Francisco, 1962.

23. Gibson J. E. Computer investigation of folded slab roofs. Struct. Engr, 1962, 40, 151-160.

24. Gibson J. E. An investigation of folded plate structures. Struct. Engr, 1964, 42, 299-304.

25. GiBson J. E. The design of shell roofs. E. \& F. N. Spon, London, 1968, chapter 12.

26. Gibson J. E. and Gardner N. J. Investigation of multi-folded plate structures. Proc. Instn Civ. Engrs, 1965, 28, 31, 57-69. Discussion, 1966, 34, 295-300.

27. Scordelis A. C. A matrix formulation of the folded plate equations. Proc. Am. Soc. Civ. Engrs, 1960, 86. ST 10, 2617.

28. Scordelis A. C. et al. Experimental and analytical study of folded plate. Proc. Am. Soc. Civ. Engrs, 1961, 87. ST12, 3023.

29. Rockey K. C. and Evans H. R. A finite element solution for folded plate structures. Proc. Conf. Space Struc. Blackwell, Oxford, 1967, 165-188. 